\title{
Conceptual Design of Temporally Storage Area in Hot Cell for Fusion DEMO Reactor ${ }^{*}$
}

\author{
Masatoshi KONDO ${ }^{1)}$, Youji SOMEYA ${ }^{2, a)}$, Mitsuyo TSUJI ${ }^{3)}$, Satoshi YANAGIHARA ${ }^{4)}$, \\ Hiroyasu $\mathrm{UTOH}^{2, a)}$, Takashi KATO, Kenji TOBITA ${ }^{2, a)}$ and Shinzaburo MATSUDA ${ }^{1)}$ \\ ${ }^{1)}$ Tokyo Institute of Technology, 2-12-1 O-okayama, Meguro-ku, Tokyo 152-8550, Japan \\ 2) Japan Atomic Energy Agency, 2-166 Omotedate, Obuchi, Rokkasyo, Aomori 039-3212, Japan \\ ${ }^{3)}$ Tokai University, 4-1-1 Kitakaname, Hiratuka, Kanagawa, 502-5292, Japan \\ ${ }^{4)}$ University of Fukui, Fukui 914-0055, Japan
}

(Received 22 November 2015 / Accepted 26 March 2016)

In the maintenance procedure of fusion DEMO reactor, used in-vessel components are removed from the reactor vessel to be replaced. The temporally storage area for the used blanket segments is necessary. In the present work, the temporally storage area is conceptually designed as the used segments are stored dispersively in the plural compartments in the hot cell for the following dismantling procedure. The space dose rate of the compartment, where more than one segment is installed, was evaluated by means of the gamma ray transport calculation with PHITS Monte Calro analysis code. The space dose rate in the compartment decreases with time. For example, by the temporally storage of five used segments in one compartment for 20 years, the space dose rate in the compartment becomes lower than $250 \mathrm{~Gy} / \mathrm{hr}$, which is the limited value proposed for the remote handling in the ITER. The decay heat of the segments during the temporally storage is removed by flowing He. The segments are cooled at the temperature lower than $550^{\circ} \mathrm{C}$. Then, the used back plates can be reused in the other operation of the reactor, since the mechanical properties of the back plates are not affected by the heat treatment during the temporally storage.

(c) 2016 The Japan Society of Plasma Science and Nuclear Fusion Research

Keywords: hot cell, segment, waste management, low-level waste, remote handling

DOI: $10.1585 /$ pfr.11.2405077

\section{Introduction}

The maintenance scenario and the waste management of fusion DEMO reactor have been proposed [1-3]. In the maintenance procedure of the reactor, used in-vessel components are removed from the reactor vessel to be replaced. Then, the low-level radioactive waste (LLW) of approximately $6000 \mathrm{t}$ is generated. The quantity of the radioactive waste can be reduced by $60 \%$ in total, if some parts of the used blanket components are reused and recycled for the other operation of the reactor [4]. However, these are radioactivated and having a large decay heat. Their dismantlement is available by the remote handling (RH) [5] only after their temporally storage for a certain period in the hot cell until the radiation level becomes low to be allowed for the RH [6]. Therefore, the temporally storage of the blanket components in the hot cell is the essential procedure for the waste management of the fusion reactors. However, the study on the temporally storage of the used blanket components in the hot cell is quite limited.

author'se-mail: kondo.masatoshi@lane.iir.titech.ac.jp

*) This article is based on the presentation at the 25th International Toki Conference (ITC25).

a) Present affiliation: National Institutes for Quantum and Radiological Science and Technology, 2-166 Omotedate, Obuchi, Rokkasho, Aomori 039-3212, Japan
It is proposed that the used blankets are removed from the vacuum vessel (VV) though the vertical port $[7,8]$ as multi module segments, which are the back plate integrated blanket module. These segments must be stored temporally in the hot cell after the removal of residual tritium by thermal detritiation process [9]. During the temporally storage of the segments, their decay heat must be removed. The segments must be cooled at the adequate temperature to suppress the effect of the heat treatment on their mechanical properties for their reuse and recycle.

In the present study, it is proposed that the used blanket segments are stored dispersively in the plural compartments of the temporally storage area in the hot cell. The motivation for this system is to achieve the reduction of the risk and the mitigation of the cooling conditions of the decay heat without the increase of total floor space required for their storage area. The changes of the space dose rate and the temperature condition in the compartment with time were investigated by means of gamma ray transport calculation and thermofluid calculation. The purpose of the present study is to propose the conceptual design of the temporally storage area in the hot cell. 


\section{Conceptual Design of Temporally Storage Area in Hot Cell}

Main parameters of the fusion DEMO reactor are presented in Table 1 [5]. This reactor is assumed to be periodically maintained every two years. After the shutdown of the reactor, the in-vessel components are cooled in the $\mathrm{VV}$ for one month. 80 pieces of the multi module segments (i.e., back plate integrated blanket segments) are removed from the reactor every two years. The weight of the segment is approximately $67 \mathrm{t}$.

The temporally storage area for the used segments in the hot cell is divided into small compartments. Figure 1

Table 1 Main parameter of fusion DEMO reactor [5].

\begin{tabular}{lll}
\hline Fusion output & {$[\mathrm{GW}]$} & 1.35 \\
\hline Major radius & {$[\mathrm{m}]$} & 8.2 \\
\hline Aspect ratio & & 3 \\
\hline Ellipticity & & 1.65 \\
\hline Thickness of the blanket & {$[\mathrm{m}]$} & 0.6 \\
\hline Neutron wall load & {$\left[\mathrm{MW} / \mathrm{m}^{2}\right]$} & 0.9 \\
\hline
\end{tabular}

(a) shows the simplified model of the segment, which has a rectangular parallelepiped shape, though the real shape of the segments has an arch-shape. This model is used to evaluate the space dose rate and the temperature conditions in the temporally storage compartment.

Figure 1 (b) shows the structure of the compartment. The wall of the compartment is made of a heavy concrete. The inner surface of the wall is covered by the lining made of stainless steel to suppress the transport of tritium released from the segment during the storage. The coolant for the decay heat removal of the used segments is a flowing He because tritium should be recovered from the coolant during the storage. The heavy concrete wall is cooled by flowing water using embedding piping system.

The plural segments are placed in the compartment and arranged as their blanket sides facing each other to have the beneficial effect of the radiation shielding by their back plates. In this case, the dose rate in the backward space of the back plates is low. This space can be available for the installation of the devices required for the monitoring system, such as the temperature measurement of the segments. The segments are arranged as a circle, and the

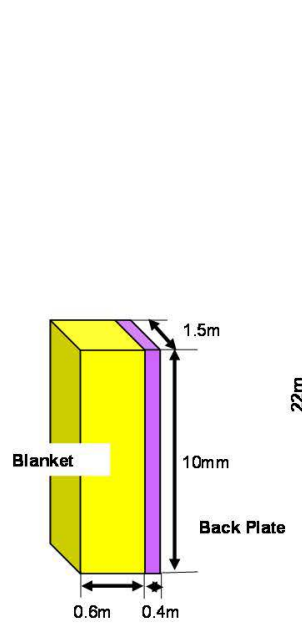

(a)

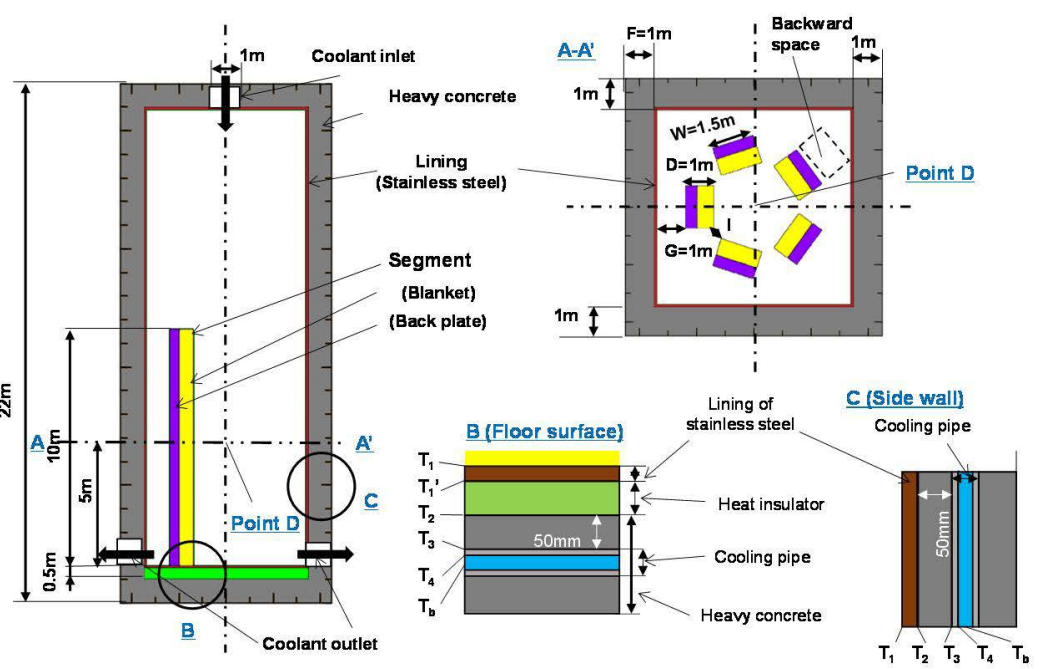

(b)

Fig. 1 Structure of (a) simplified model of the segment having a rectangular parallelepiped shape and (b) temporally storage compartment.

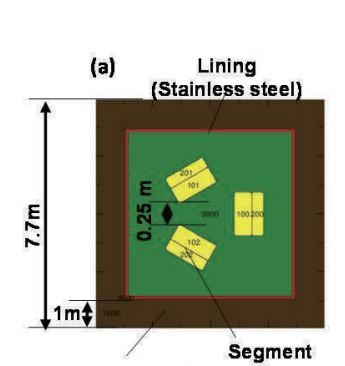

Heavy concrete wall (b)

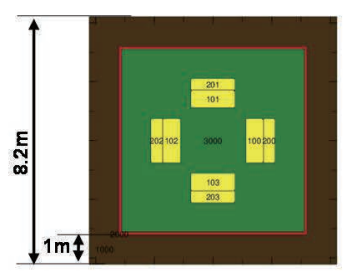

(c)

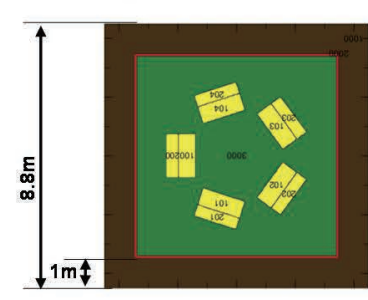

(d)

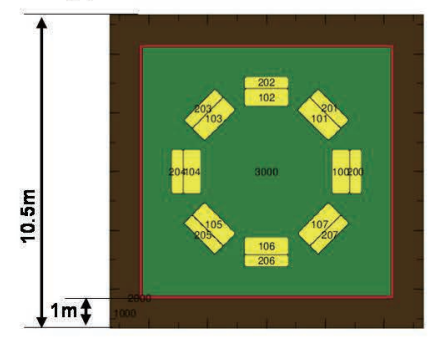

Fig. 2 Plan view of segment installation with interval of $0.25 \mathrm{~m}$ in compartment (a) 3 segments installation, (b) 4 segments installation, (c) 5 segments installation, (d) 8 segments installation. 
example for the installation of plural segments in one compartment is shown in Fig. 1 (b) and Fig. 2. Then, the total floor space, $S_{\text {total }}$, required for the temporary storage of all the segments is expressed as

$$
\begin{aligned}
S_{\text {total }}= & \left((W+1) \times \frac{n}{\pi}+(F+D+G) \times 2\right)^{2} \\
& \times \frac{N_{\text {segments }}}{n} .
\end{aligned}
$$

Here, the width, $W$, and the thickness, $D$, of the segment are $1.5 \mathrm{~m}$ and $1 \mathrm{~m}$, respectively. The interval between the adjoining segments is given as $I$. The number of the segments installed in one compartment is given as $n$. The number of the segments in total, $N_{\text {segments }}$, is 80 . The thickness of the heavy concrete wall, $F$, is $1 \mathrm{~m}$. The gap between the segment and the wall, $G$, is $1 \mathrm{~m}$. The height of the compartment assumed as $22 \mathrm{~m}$ considering the space for the installation device of the shipping cask [8].

The total floor space required for the storage of 80 segments is evaluated by Eq. (1), and the results are shown in Fig. 3. The total floor area for the temporally storage becomes larger by increasing the number of segments installed in one compartment as shown in Fig. 3 (a). It is also found that the curve of the graph has a downward convex when the number of segments and/or the interval are

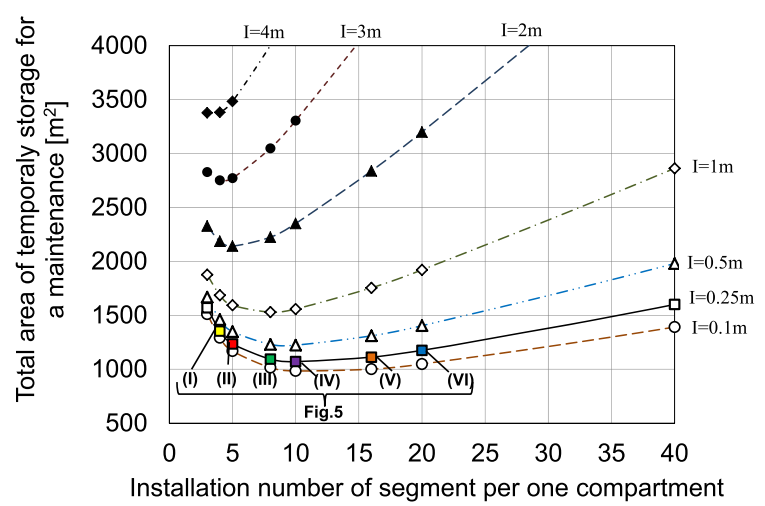

(a)

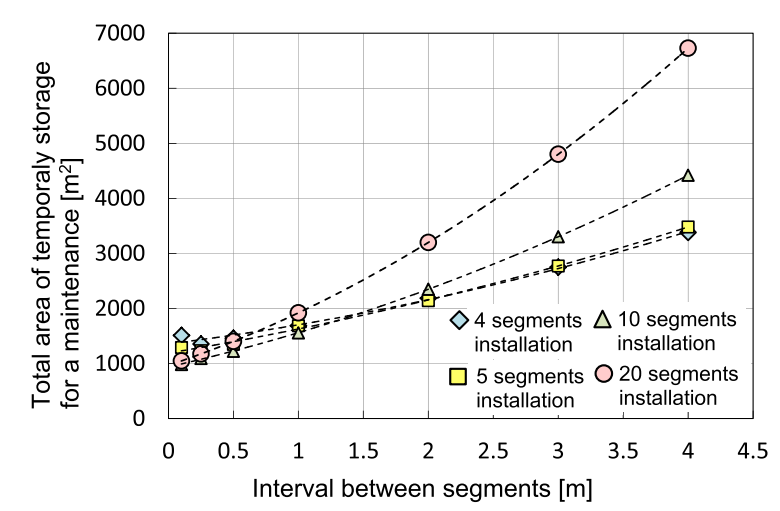

(b)

Fig. 3 Total floor space required for temporally storage (a) effect of installation number, (b) effect of interval between segments. small. Then, there are some cases which can achieve the space-saving by the installation of plural segments in the compartment.

Figure 3 (b) shows the influence of the interval $(I)$ on the total floor area of the temporally storage. The arrangement of the segments with smaller interval results to smaller total area. The increasing ratio of the total floor area by increasing the interval becomes larger when the number of segments installed in one compartment is larger. On the contrary, the influence of the interval on the total storage area is negligibly small when the interval is less than $0.5 \mathrm{~m}$. The decay heat removal by flowing He should be achieved even when the segments are installed with the small interval. The conditions of the interval: $I=0.25 \mathrm{~m}$ and the gap: $G=1 \mathrm{~m}$ are selected as one example in the current work based on above mentioned consideration.

\section{Conceptual Design of Temporally Storage Compartment in Hot Cell}

\subsection{Evaluation of space dose rate in tempo- rally storage compartment in hot cell}

Figure 4 shows the concentration of radioactive nuclides in the blanket and the back plate after the shutdown, which were obtained by the neutronic calculation by THIDA-2 code with the nuclear data library FENDL2.0 [5]. The radio nuclides, which mainly influence on the dose rate and the decay heat, are ${ }^{54} \mathrm{Mn},{ }^{55} \mathrm{Fe}$ and ${ }^{56} \mathrm{Mn}$. ${ }^{56} \mathrm{Mn}$ has short half-life of $2.5785 \mathrm{~h} .{ }^{54} \mathrm{Mn}$ and ${ }^{55} \mathrm{Fe}$ emit gamma ray of $0.8 \mathrm{MeV}$ and characteristics $\mathrm{X}$ ray of $6 \mathrm{keV}$, respectively. The contribution of latter one on the dose rate and the decay heat is small. Therefore, the space dose rate in the temporary compartment was evaluated as the segments emit $0.8 \mathrm{MeV}$ gamma ray in the present work.

The wall of the compartment is made of a heavy concrete for the purpose of the radiation shielding. Table 2 presents the chemical composition of the heavy concrete. The linear attenuation coefficient of the heavy concrete is

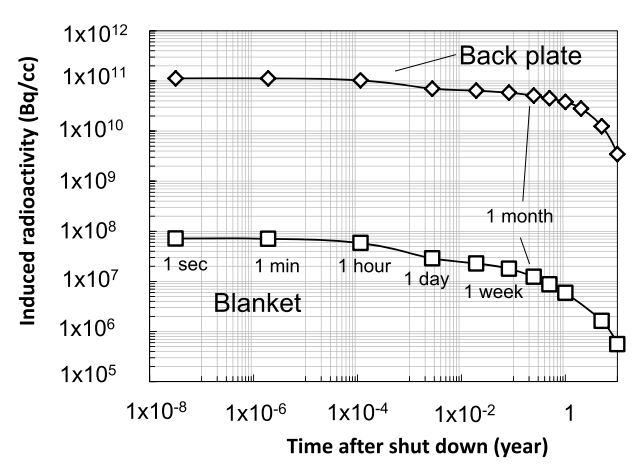

Fig. 4 Induced radioactivity of blanket and back plate.

Table 2 Chemical compositions of heavy concrete (wt \%).

\begin{tabular}{llllllll}
\hline $\mathrm{H}$ & $\mathrm{O}$ & $\mathrm{Mg}$ & $\mathrm{Al}$ & $\mathrm{Si}$ & $\mathrm{K}$ & $\mathrm{Ca}$ & $\mathrm{Fe}$ \\
\hline 0.416 & 50.7 & 0.115 & 0.446 & 38.6 & 0.07 & 6.87 & 2.74 \\
\hline
\end{tabular}


(I)

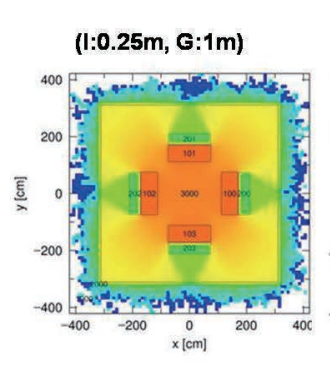

(II)

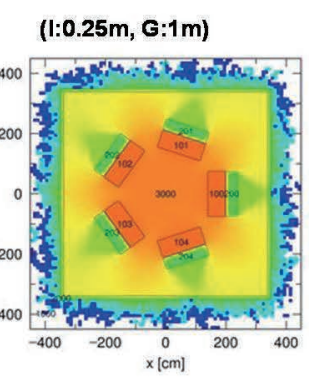

(III)

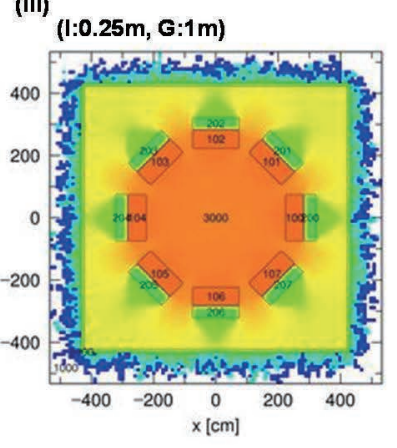

(IV) $\quad(1: 0.25 \mathrm{~m}, \mathrm{G:1 \textrm {m } )}$

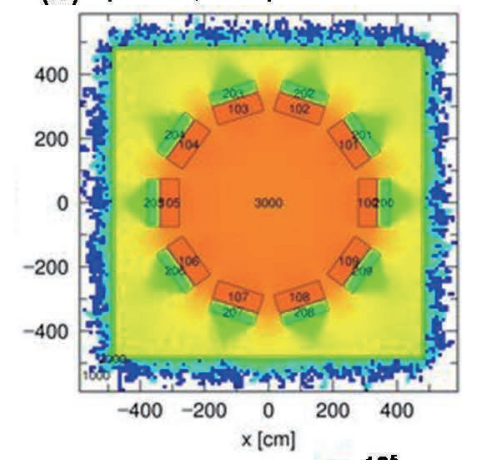

(V) $\quad(1: 0.25 \mathrm{~m}, \mathrm{G}: 1 \mathrm{~m})$

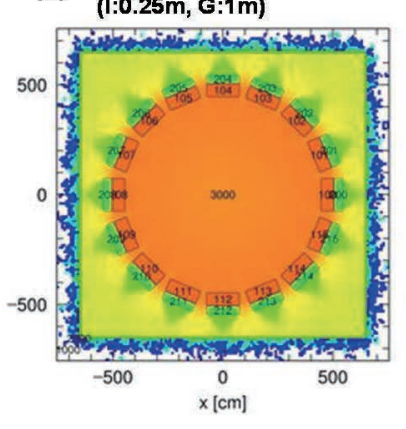

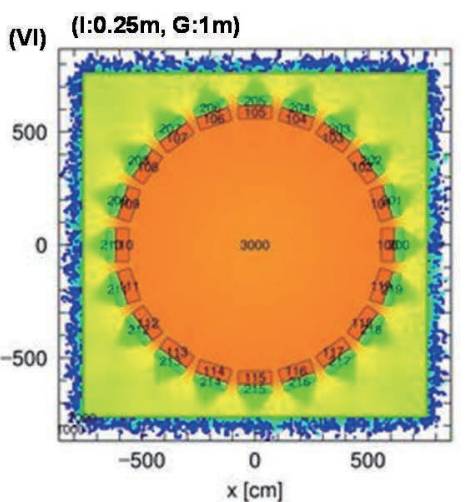
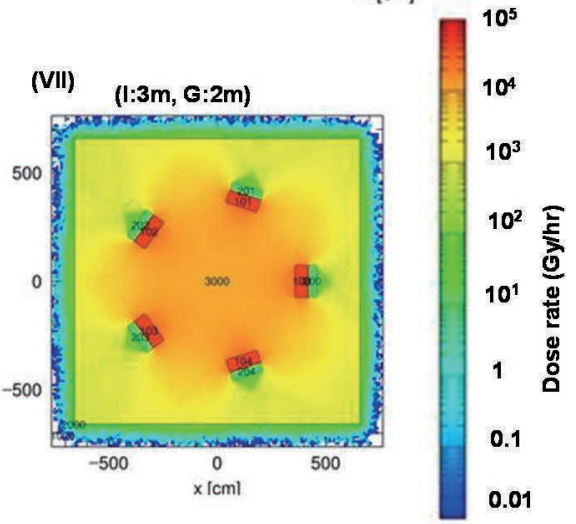

Fig. 5 Space dose rate on horizontal plane at level of $5 \mathrm{~m}$ from floor surface in compartment after one month of shut down, (I) 4 segments installation, (II) 5 segments installation, (III) 8 segments installation, (IV) 10 segments installation, (V) 16 segments installation, (VI) 20 segments installation and (VII) 5 segments installation with larger interval and gap.

estimated as $1.53 \times 10^{-1} \mathrm{~cm}^{-1}$. The thickness of the heavy concrete is $1 \mathrm{~m}$, and then the energy of gamma ray can be reduced to less than $1 \mathrm{eV}$ by this heavy concrete wall.

The space dose rate in the compartment time is simulated by the gamma ray transport calculation with PHITS Monte Calro analysis code. The geometries are shown in Figs. 1 and 2. The segments are cooled in the VV for one month. Therefore, the gamma ray transport calculation was performed with the conditions, where the induced radioactivity of the used segments corresponds to that after one-month cooling in VV (Fig. 4).

Figure 5 shows some examples of the gamma ray transport calculation of the temporally storage compartment. Fig. 5 indicated the distribution of the space dose rate on a horizontal plane at the level of $5 \mathrm{~m}$ from the floor surface. The total floor space of the temporary storage area in these cases is indicated in Fig. 3 (a). The dose rate around the center region is higher than the other part in the compartment. The space dose rate in a backward space of the back plate is lower than the other part. The space dose rate in the backward space is lower than $250 \mathrm{~Gy} / \mathrm{h}$ even at the start of the temporally storage. Figure 5 (VII) shows the distribution of the space dose rate when the segments are installed with larger interval and gap. The backward space of the segments with small dose rate is larger than that by the arrangement with narrow interval and gap (Fig. 5 (II)). However, total floor space of the temporally storage area becomes larger as shown in Fig. 3 (b).

The pentagonal arrangement of the segments has the advantage as all the diagonal lines between the segments are the same length. These diagonal lines do not intersect in one point. These features make the gentle distribution of the dose rate in the compartment, and result to suppress the formation of the hot spot in the compartment. This feature may allow the margin for the consideration of the dismantle procedures in the hot cell and/or the transport of the dismantled segments. The calculation results for the dose rate and the decay heat removal in the case of pentagonal arrangement of the segments in the compartment are mainly reported in this paper.

Figures $6(\mathrm{a}-1)$ and (a-2) show the distribution of the space dose rate in the compartment one month after the shutdown of the reactor. The dose rate at the center region is higher than the other part in the compartment. The dose rate in the center region has the peak around the level of $5 \mathrm{~m}$ from the floor surface, where is indicated as Point D in Fig. 1. The dose rate in the VV of the ITER after the plasma shutdown is estimated as $250 \mathrm{~Gy} / \mathrm{h}$, and the in-vessel components are going to be maintained by $\mathrm{RH}$ [4]. Therefore, it is assumed that the segments can be monitored and dismantled by $\mathrm{RH}$ under the dose rate of $250 \mathrm{~Gy} / \mathrm{h}$ based on the technological basis for the ITER RH. Figures $6(b-1)$ and (b-2) shows the dose rate in the compartment 10 years after the shutdown. The dose rate 


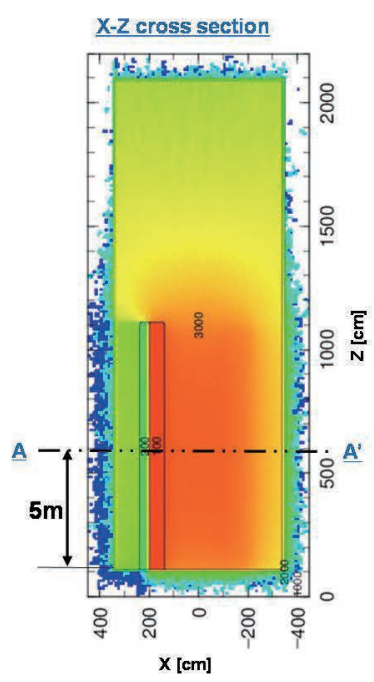

(a-1)

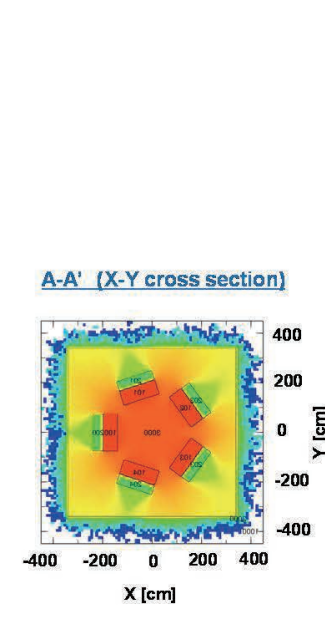

(a-2)

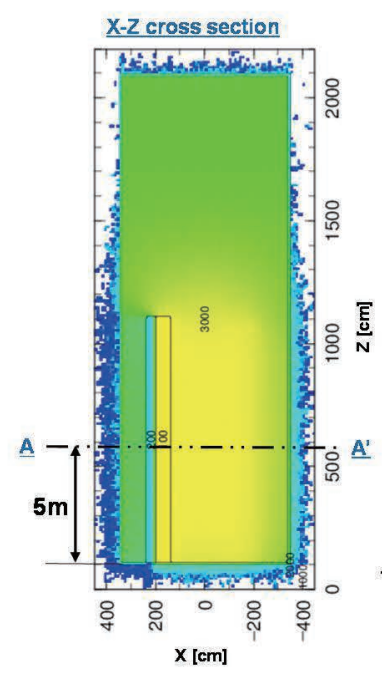

(b-1)

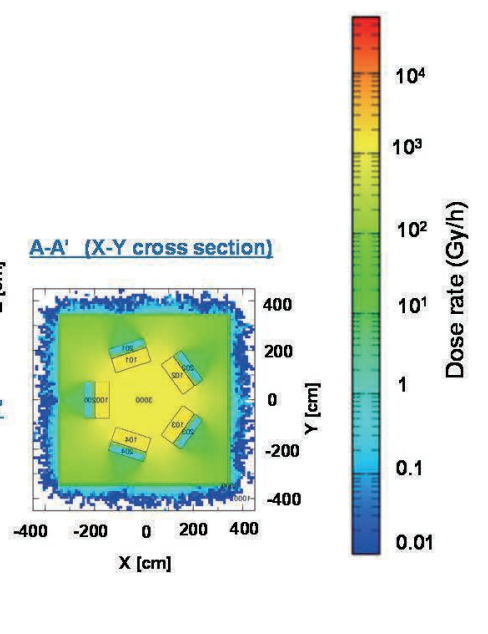

(b-2)

Fig. 6 Space dose rate of temporally storage compartment (a-1) X-Z cross section after one month from shutdown (a-2) X-Y cross section after one month from shutdown (b-1) X-Z cross section after 10 years from shutdown (b-2) X-Y cross section after 10 years from shutdown.

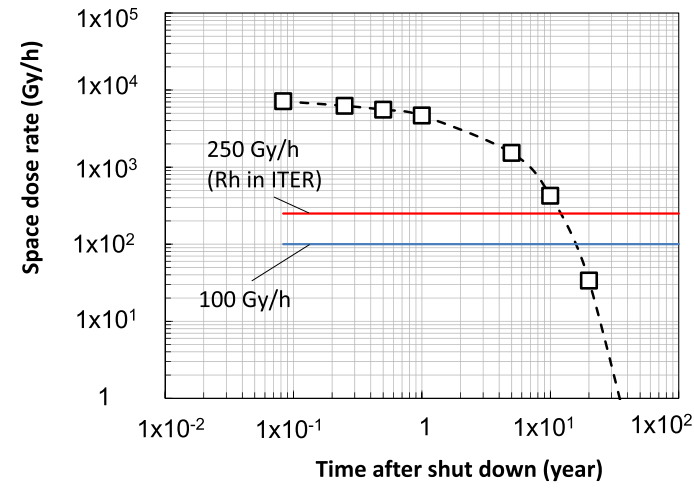

Fig. 7 Dose rate at center of compartment and at Point D in Fig. 1 (b).

becomes lower than $250 \mathrm{~Gy} / \mathrm{h}$ except for the center region, and the distribution of the space dose rate becomes small. Figure 7 shows the change of the dose rate at the Point $\mathrm{D}$ with time. The space dose rate in all the part of the compartment becomes lower than $100 \mathrm{~Gy} / \mathrm{h}$ after the temporally storage for 20 years.

\subsection{Removal of decay heat in temporally storage compartment of hot cell}

Figure 8 shows the decay heat for one segment. After the cooling of the segments in the $\mathrm{VV}$ of the reactor, the used segments are transported from the reactor vessel to the compartment using the shipping cask [8]. The total floor space of the temporary storage area is estimated as less than $1500 \mathrm{~m}^{2}$ (Fig. 3). For example, the maximum moving distance of the segment in the temporally storage area is roughly estimated as $77.5 \mathrm{~m}(=2 \times \sqrt{1500})$ based on the assumption as the temporary storage area has

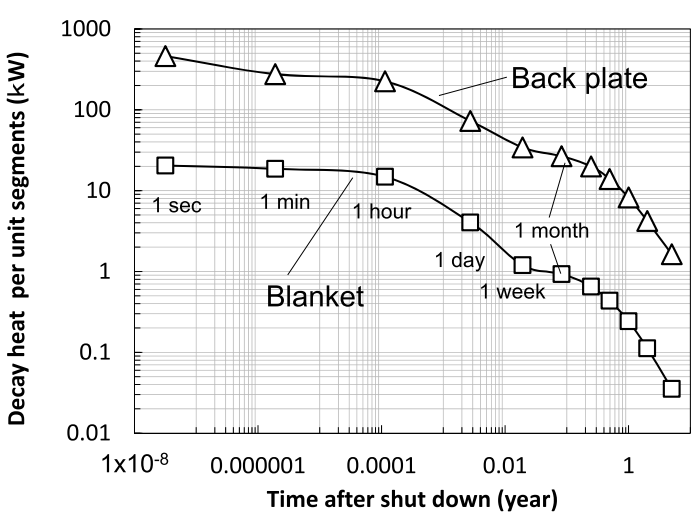

Fig. 8 Decay heat of blanket and back plate in one segment.

a square shaped floor. It is assumed that the transport speed of the segment by an overhead crane may not be less than $1 \mathrm{~m} / \mathrm{min}$ considering the transport speed of the spent fuel in the spent fuel reprocessing plant [10]. Therefore, the time required for the segment transport must be less than 1.5 hour. Then, the time for the transport of the segment by the cask including the mounting and the dismounting of the segment into/from the cask can be roughly estimated as less than 5 hours. The temperature increase of the segment by the decay heat in this procedure is less than $30 \mathrm{~K}$.

Architectural Institute of Japan $[11,12]$ proposed that the limiting temperature of the heavy concrete wall is $338 \mathrm{~K}$. Therefore, the temperature of the heavy concrete wall ( $\mathrm{T}_{2}$ in Fig. $\left.1(\mathrm{~b})\right)$ in the temporally storage compartment should be lower than $65^{\circ} \mathrm{C}$. The temperature of the segments installed in the compartment is evaluated by the CFD code PHOENICS. Here, the decay heat after the cooling for one month (Fig. 8) in the VV is applied in the cal- 
Table 3 Thermal properties of materials used in layer structure of wall.

\begin{tabular}{llll}
\hline & Material & Thickness or size $[\mathrm{mm}]$ & $\begin{array}{l}\text { Thermal } \\
{[\mathrm{W} / \mathrm{mK}]}\end{array}$ \\
\hline Lining & 304 type austenitic steel & 50 & 16.0 \\
\hline Heat insulator & Glass wool & 500 & 0.05 \\
\hline Heavy concrete & (See table1) & 50 & 1.2 \\
\hline Cooling pipe & 304 type austenitic steel & 1 inch tube (thickness: 1.2$)$ & 16.0 \\
\hline
\end{tabular}

culation to check the coolability of the compartment. The decay heat of the segment is removed by flowing $\mathrm{He}$ in the compartment. The inlet port having a rectangular cross sectional channel is located on the top of the compartment as shown in Fig. 1 (b). Two outlet ports having a rectangular cross sectional channel are located at the bottom part of the side walls. The size of these ports is $1 \mathrm{~m}^{2}$. The flow rate of the flowing $\mathrm{He}$ is $60 \mathrm{~m}^{3} / \mathrm{min}$. The wall of the compartment has the layer structures as shown in Fig. 1 (b). The thermal properties of the materials used in the wall is summarized in Table 3. The coolability of the heavy concrete wall is roughly evaluated with one-dimensional model. Here, the Reynolds number of flowing water is 2567 , and the bulk temperature ( $\mathrm{T}_{\mathrm{b}}$ in Fig. $1(\mathrm{~b})$ ) is $303 \mathrm{~K}$. Then, the surface temperature of the concrete wall $\left(\mathrm{T}_{2}\right.$ in Fig. 1 (b)) can be kept as less than $313 \mathrm{~K}$ by the flowing water, even when the temperature of the $T_{1}$ is $473 \mathrm{~K}$. Therefore, it is found that the temperature of the concrete wall is kept at the temperature less than $313 \mathrm{~K}$ by the water cooling.

Figure 9 shows the temperature distribution in the compartment. The temperature of the back plates should be lower than $550{ }^{\circ} \mathrm{C}$ to suppress the effect of this heat treatment on their mechanical properties for their reuse. It was found that the temperature of the segments was around the $150{ }^{\circ} \mathrm{C}$ at the steady state condition.

\section{Conclusion}

The temporally storage area for the used blanket segments is conceptually designed to investigate in detail the maintenance procedure of fusion DEMO reactor. Major conclusions are follows;

(1) The used segments are stored dispersively in the plural compartments in the hot cell for the following dismantling procedure. The total floor space required for the temporally storage of 80 segments are estimated as less than $1500 \mathrm{~m}^{2}$.

(2) The wall of the temporally storage compartment, which is made of a heavy concrete, has high shielding performance for the $\gamma$ ray emitted from the used segments. The linear attenuation coefficient of the heavy concrete is estimated as $1.53 \times 10^{-1} \mathrm{~cm}^{-1}$.

(3) The distribution of the space dose rate in the compartment, in which five segments were installed, was evaluated by means of the gamma ray transport cal-
A-A' (X-Y cross section)

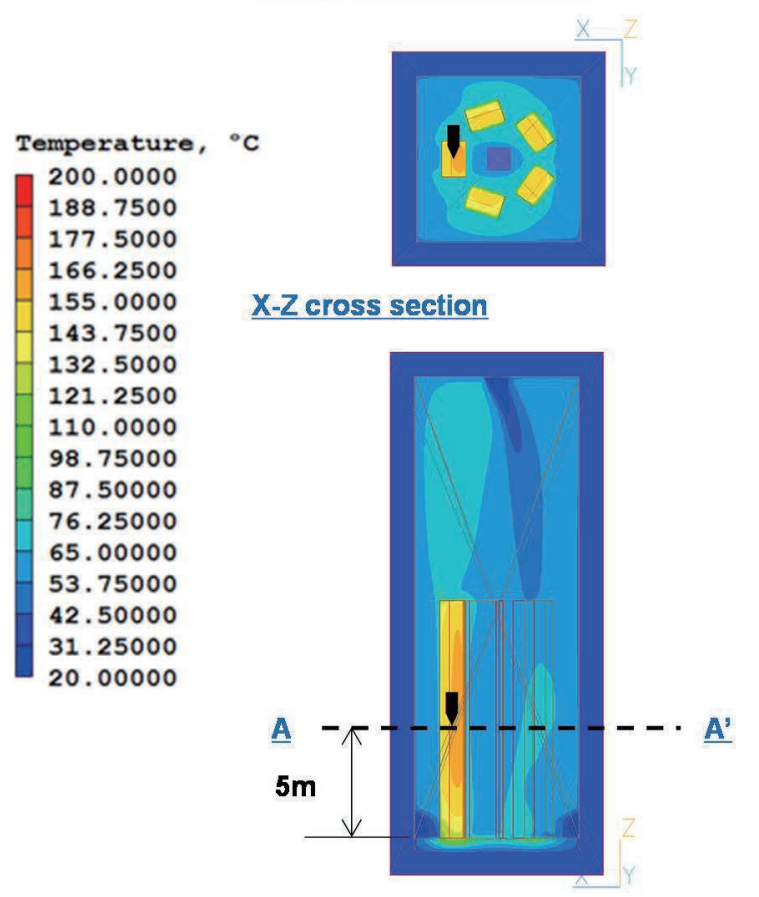

Fig. 9 Temperature distribution in compartment by 5 segments installation.

culation with PHITS Monte Calro analysis code. The backward space of the segments has lower space dose rate than that in the other part. This distribution is due to the beneficial effect of the back plate as the radiation shielding. The space is available for the installation of some devices required for the monitoring of segment's temperature.

(4) The space dose rate in the temporally storage compartment decreased according to the decay of the radioactive nuclides in the used segments. The space dose rate in the compartment becomes lower than the value proposed for the remote handling in the ITER when five segments are cooled in the compartment for 10 years.

(5) The results of the thermofluid simulation using the PHOENICS code showed that the decay heat during the temporally storage of the segments can be removed by flowing $\mathrm{He}$. It was found that the segments can be kept at the temperature lower than $550^{\circ} \mathrm{C}$ to suppress the effect of the heat treatment on the me- 
chanical properties of the back plate. Then, the reuse of the used back plates in the other operation of the reactor is available, and significantly reduces the generation of the low-level radioactive waste.

\section{Acknowledgments}

This work was partially supported by the Japan Atomic Energy Agency under the Joint Work contract 27K422, as a part of Broader Approach activities. The author would thank Mr. Y. Nakajima in Tokai university for the technical support on gamma ray transport calculation and Mr. Y. Noguchi in QST for the fruitful discussion about the remote maintenance technologies of fusion reactors.

[1] Y. Seki, I. Yamauchi, K. Yamada and H. Kawasaki, J. Fusion Energy 3, No.4, 241 (1983).

[2] Y. Seki, I. Aoki, N. Yamano and T. Tabara, J. Fusion Energy 16, No.3, 205 (1997).

[3] K. Tobita, S. Nishio, S. Konishi and S. Jitsukawa, J. Nucl. Mater. 329-333, 1610 (2004).

[4] Y. Someya, K. Tobita, S. Yanagihara, M. Kondo, H. Utoh, N. Asakura, K. Hoshino, M. Nakamura and Y. Sakamoto,
Fusion Eng. Des. 89, 2033 (2014).

[5] Y. Someya, K. Tobita, M. Kondo, S. Yanagihara, H. Utoh, N. Asakura, K. Hoshino, M. Nakamura and Y. Sakamoto, In proceedings of Plasma 2014, 21pE-1, Niigata, Japan, Nov. 18-21 (2014).

[6] T. Maruyama, Y. Noguchi, N. Takeda and S. Kakudate, Plasma Fusion Res. 10, 3405010 (2015).

[7] H. Utoh, K. Tobita, Y. Someya and H. Takase, Fusion Eng. Des. 87, 1409 (2012).

[8] M. Coleman, N. Sykes, D. Cooper, D. Iglesias, R. Bastow, A. Loving and J. Harman, Fusion Eng. Des. 89, 2347 (2014).

[9] Y. Torikai, R.-D. Penzhorn, in proceedings of 10th international conference on tritium science and technology, Nice, France, Oct. 21-25 (2013).

[10] Repair/maintenance remote handling equipments design for tokamak experimental fusion reactor, JAERI-M 8370 (1979).

[11] Draft guide line and review for concrete for container vessel of nuclear power plant, Architectural Institute of Japan (in japanese) (1978).

[12] An experimental study on mechanical properties of concrete exposed to high temperature conditions for eight years, CRIEPI, Abiko Research Laboratory Report, No. U95037 (1996). 